\title{
Sinapsien ikuspegi modernoa: zelulaz kanpoko matrizearen funtzioa konexio neuronalean
}

\author{
(Modern view of synapses: extracellular matrix function \\ in neuronal connection)
}

Amaia Núñez del Moral*, Amaia Maite Erdozain Fernandez

Farmakologia saila, Euskal Herriko Unibertsitatea (UPV/EHU)

*amaianm13@gmail.com

DOI: $10.1387 /$ ekaia.19676

Laburpena: Sinapsiaren azkeneko teoriak, sinapsi tetrapartitak, laugarren partaide bat gehitzen du neuronen arteko informazio garraioan eta birmoldaketa sinaptikoan: zelulaz kanpoko matrizea (ZKMa). Era honetan, konexio neuronalen osagaiak neurona presinaptikoa, neurona postsinaptikoa, glia eta ZKMa izango lirateke. ZKMa zelulen kanpoaldean dauden eta funtzio ezberdinak dituzten zenbait molekulak osatzen dute. Haren garrantzia ez da funtzio fisiologikora mugatzen, izan ere bere funtzioen alterazioak neurogarapenezko gaixotasunak eta gaitz neurologikoak eta neuropsikiatrikoak ere ekar baititzake. Ondorioz, ZKMa gaur egun osasun-zientzietarako funtsezko tresna da, ikertu eta aztertu beharrekoa. Lan honetan, lehendabizi, sinapsi bipartitaren eta sinapsi tripartitaren teoriak laburki azaltzen dira, ondoren sinapsi tetrapartitaren kontzeptuan barneratzeko. Amaitzeko, ZKMaren inguruko azkeneko aurkikuntzen garrantzia hainbat patologiatan aipatzen dira.

Hitz gakoak: sinapsia, zelulaz kanpoko matrizea, astrozitoak, sare-neuronala, plastikotasun sinaptikoa.

Abstract: The last theory about synapse, called tetrapartite synapse, adds a fourth partner in the information transport between neurons and synaptic remodeling: the extracellular matrix $(\mathrm{ECM})$. In this way, presynaptic neuron, postsynaptic neuron, glia and ECM should be the neuronal connections elements. ECM is constituted by a lot of molecules with different function and by the interactions between them. Its relevance is also related to its functional alterations, which could derive in neurodegenerative diseases and neuropsychiatric disorders. In conclusion, nowadays ECM is an essential tool for the health science that has to be studied and investigated. In the present article, 
we first briefly explain the bipartite and tripartite synapse theories, and we then focus on the tetrapartite synapse concept. Finally, the relevance of the latest findings over the ECM in some pathologies are mentioned.

Keywords: synapse, extracellular matrix, astrocytes, neuronal network, synaptic plasticity.

\section{SARRERA}

Egun, ohikoa da konexio neuronalekin erlazionatutako berriak entzutea, eta teknologiaren aurrerakuntzei esker lortutako inteligentzia artifiziala horren adibide ona da. Baina hura lortzea ez da erraza, organo honen konplexutasuna amaigabea ematen baitu batzuetan. Zenbat eta gehiago aurkitu gutxiago dakigu haren bene-benetako mekanismoez. Hortaz, burmuinak nola funtzionatzen duen jakiteko ezinbestekoa da lehenengo neuronen arteko informazioaren garraioa nola gertatzen den jakitea.

Garuna atal ezberdinetan banatuta dago eta atal bakoitzak funtzio zehatz bat du. Estimulu baten aurrean garun atal jakin batzuk aktibatzen dira, bakoitzak ingurunetik informazio zehatz bat hartuz. Informazio ugari eta ezberdin horri forma eta zentzua emateko, garun atalek elkarri eragin behar diote. Horretarako, neuronek beraien arteko konexio askotarikoak sortzen dituzte, sare neuronalak alegia. Baina garunaren sare neuronalak, sare neuronal artifizialak ez bezala, ez dira estatikoak, dinamikoak baizik. Hau da, bizitzan zehar sare neuronalak aldatuz doaz. Batetik, zirkuitu sinaptiko hauek jaio ondoren gehiegizko konexioz osatuta daude eta erabiltzen ez diren konexioak apurtu egin behar dira (inauste sinaptikoa). Nahiz eta garun helduan sinapsien ezabatzea hain nabarmena ez izan, oraindik gertatzen jarraitzen du. Bestetik, sinapsien hazkuntza ere gertatzen da, kasu honetan esperientzien bidezko sinapsien indartzearen ondorioz [1, 2]. Eta zer dakigu gaur egun konexio neuronal honi buruz? Zeri deritzogu informazio neuronala? Nola garraiatzen da? Zer-nolako eraginak izan ditzakete sinapsien alterazioek gaitz neurologiko eta psikiatrikoetan? Galdera hauek modu argi batean erantzuteko, bi egiturez osatutako sinapsi «tradizionala»ren teoria azaltzen hasiko gara eta azkenengo teoria azaltzen amaitu, sinapsi tetrapartita.

\section{SINAPSI BIPARTITA}

Normalean sinapsi kimikoa funtsezko bi egiturak osatzen dute: neurona presinaptikoa eta postsinaptikoa. Aipatu den bezala bi egitura hauen artean ez dago kontaktu zuzenik: haien artean tarte bat dago, espazio sinaptiko deritzona. 
Neurona presinaptikoaren terminal sinaptikoak neurotransmisoreak gordetzen dituzten besikula izeneko organuluak ditu. Neurotransmisoreak (NT) mezulari-lanetan jokatzen duten molekula kimikoak dira. Axoietatik garraiatutako seinale elektrikoak (ekintza potentziala) mintz presinaptikoaren potentzialaren aldaketa eragiten du terminal sinpatikoan. Potentzial elektrikoaren aldaketa honek mintzean dauden potentzial-diferentziaren menpeko kaltzio erretenak ireki eta kaltzio ioiaren $\left(\mathrm{Ca}^{2+}\right)$ sarrera bultzatzen du. Zelula-barruko $\mathrm{Ca}^{2+}$ kontzentrazioaren igoeraren ondorioz, besikula sinpatikoak terminal sinaptikoaren mintzarekin fusionatzen dira eta NTa espazio sinaptikoan askatzen da [3].

Ondoren, neurotransmisoreak neurona postsinaptikoan dauden hartzaile espezifikoekin lotuko dira, ekintza-potentzial berri baten sorrera sustatuz edo eragotuz. Funtsean, bi motatako hartzaile neuronalak daude:

1. Hartzaile ionotropikoak: estekatzaile jakin batek irekitako edo itxitako erreten ionikoak. Kanal ionikoaren egituraren aldaketak neurona postsinaptikotik ioi espezifikoen sarrera edo irteera eragiten du.

2. Hartzaile metabotropikoak: molekula bitartekari batzuen bidez (G-proteinak) kanal ionikoen egitura aldatu dezakete eta zelulabarruko mezulari sekundarioen aktibazioa edo inhibizioa eragiten dute [4].

Bere eginkizuna bete ostean, neurotransmisoreak espazio sinaptikotik desagertu behar dira. Horretarako bi motatako mekanismoak erabiltzen ditu nerbio-sistemak: proteina garraiatzaile espezifikoak eta entzimak. Proteina garraiatzaileak neurona presinaptikoaren mintz plasmatikoan daude eta NTak espazio sinaptikotik zitoplasmara barneratzen dituzte. Entzimek, aldiz, molekularen egitura aldatuz NTak degradatzen dituzte. Bi mekanismo hauek aldi berean gerta daitezke neurotransmisore motaren arabera [5].

Prozesu hau guztia behin eta berriro errepikatzen da ekintza potentzialak heltzen diren heinean, bi egituraz osatutako ziklo bat sortuz: sinapsi bipartita (Ikus 1.irudia). 


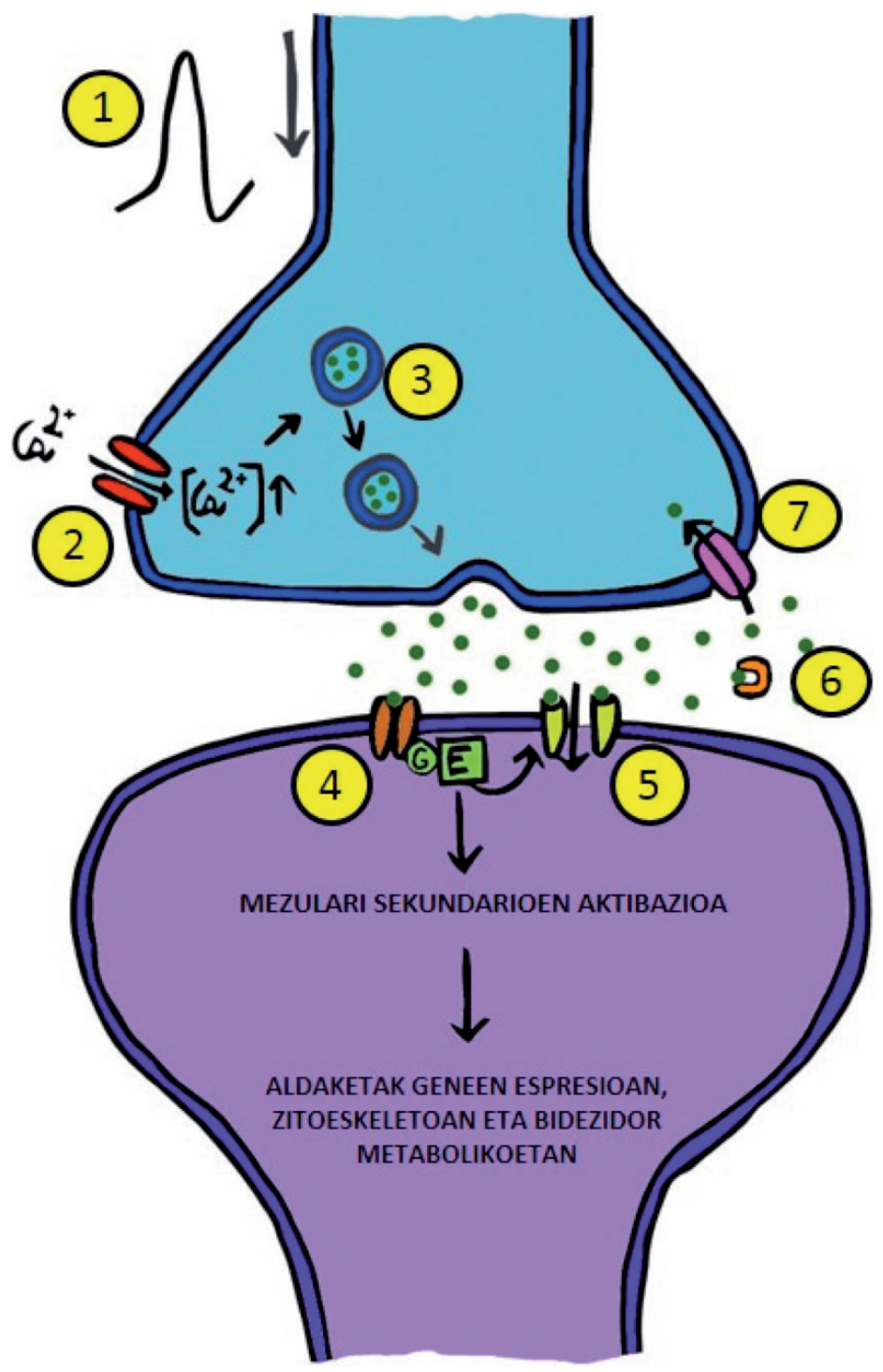

1. irudia. Sinapsi bipartitaren seinaleztapen-sistemaren eskema. 1) Mintz plasmatikoaren despolarizazioa eta ekintza-potentzialaren garraioa mintzean zehar. 2) Kaltzio kanalen irekitzea eta ioiaren sarrera zitoplasmara. 3) Zelulaz barneko kaltzio kontzentrazioaren handipenak besikulen mugimendua eta beraien fusioa mintz plasmatikoarekin eragiten du. Ondorioz, neurotransmisorearen askapena gertatzen da. 4) Neurotransmisoreen lotura hartzaile metabotropikoekin. 5) Neurotransmisoreen lotura kanal ionikoekin. 6) Entzimen bidezko neurotransmisorearen degradazioa. 7) Neurotransmisoreen barneratze neuronala proteina garraiatzaileen bidez. 


\section{SINAPSI TRIPARTITA}

Garunean, neuronez gain, badira beste zelula batzuk ere: glia izeneko zelulak. Glia ekintza-potentziala sortu eta garraiatu ezin duten zelula neuralen multzo zabala da eta bakoitzak bere funtzio zehatza du. Baina orokorrean, gliak neuronak eta sinapsiak inguratzen ditu, neurotransmisioaren euskarri-lanetan jokatuz, kanpoko espazioan oreka ionikoa mantenduz eta ekintza-potentzialaren abiadura handitzeko axoiak isolatuz. Beraz, zelula hauek aldamioek eraikinetan betetzen duten funtzioa bezalakoa burutzen dute burmuinean [6]. Astrozitoak (edo astroglia) izar itxurako zelula glial ugarienak dira nerbio sistema zentralean. Hauek neuronentzat beharrezkoak diren nutrientez hornitzen dituzte neuronak, burmuinera heltzen den odol-fluxua kontrolatzen dute, prozesu metabolikoen ondoriozko hondakinak garbitzen dituzte, eta glutamato neurotransmisorearen kasuan, sinapsian soberan geratzen den glutamatoa hartu, metabolizatu eta neurona presinaptikoari bueltatzen diote neurotransmisorearen birziklapen biologikoa eginez [7-10].

1999. urtean Alfonso Araque ikertzaileak, astrozitoen azkenengo ikerkuntzen emaitzak ikusita, sinapsiaren hirugarren partaidetzat proposatu zituen astrozitoak. Lan honekin, Araque-k sinpasi tripartitaren teoria eraiki zuen [11]. Hortik aurrera lan anitzak egin dira sinapsi tripartitaren mekanismo molekularrak ulertzeko helburuarekin. Sinplifikatuz, honako hau izango zen haren funtzionamendua.

Sinapsi glutamatergikoek (non neurona presinaptikoak glutamatoa askatzen duen) konexio neuronal kitzikatzaile ugarienak osatzen dituzte [12]. Testuinguru honetan, sinapsi bipartitaren teorian oinarrituko bagina, neurona presinaptikoak askatutako glutamatoa neurona postsinaptikoan dagoen hartzaileari lotu eta potentzial elektrikoaren aldaketa eragingo luke, neurona hori kitzikatuz. Baina astrozitoek paper garrantzitsua jokatzen dute sinapsi hauetan. Nahiz eta urte askotan pentsatu izan zen astrozitoak elementu pasiboak zirela nerbio kinadan, azkeneko ikerkuntzek erakutsi dute modu aktibo batean parte hartzen dutela transmisio sinaptikoan. Alde batetik, neurona presinaptikoak glutamatoa askatzen duenean astrozitoek bere mintzetan duten glutamatoarentzako garraiatzaileek glutamatoa xurgatzen dute. Modu honetan, tarte sinaptikoan neurotransmisore kantitatea murrizten dute, glutamatoaren hartzaileen aktibazioa eta erantzun sinaptikoa kontrolatzeko helburuarekin. Beste aldetik, tarte sinaptikoan dagoen glutamatoa astrozitoek bere mintzetan espresatzen duten glutamatoarentzako hartzaileetara lotzen zaie eta ondorioz astrozitoek bere barne-egituretan gordetzen duten kaltzioa zitoplasmara askatzen da. Neurona presinaptikoetan gertatzen den bezala, kaltzio ioiaren zelula barneko kontzentrazioaren igoerak besikulen eta mintz plasmatikoaren fusioa eragiten du, hauen edukiaren jariapena espazio sinaptikora bultzatuz. Kasu honetan astrozitoek 
ere biomolekula transmisoreak askatzen dituzte, gliotransmisore izenekoak. Gliotransmisoreek neurona presinaptikoetan eta postsinaptikoetan hartzaile espezifikoak dituztenez, transmisio sinaptikoetan eragina dute: neurona presinaptikoaren glutamatoaren askapena sustatzen edo murrizten dute eta neurona postsinaptikoan dauden glutamatoarentzako hartzaileen kitzikapen gaitasuna aldatzen dute [13-15]. (Ikus 2. irudia).

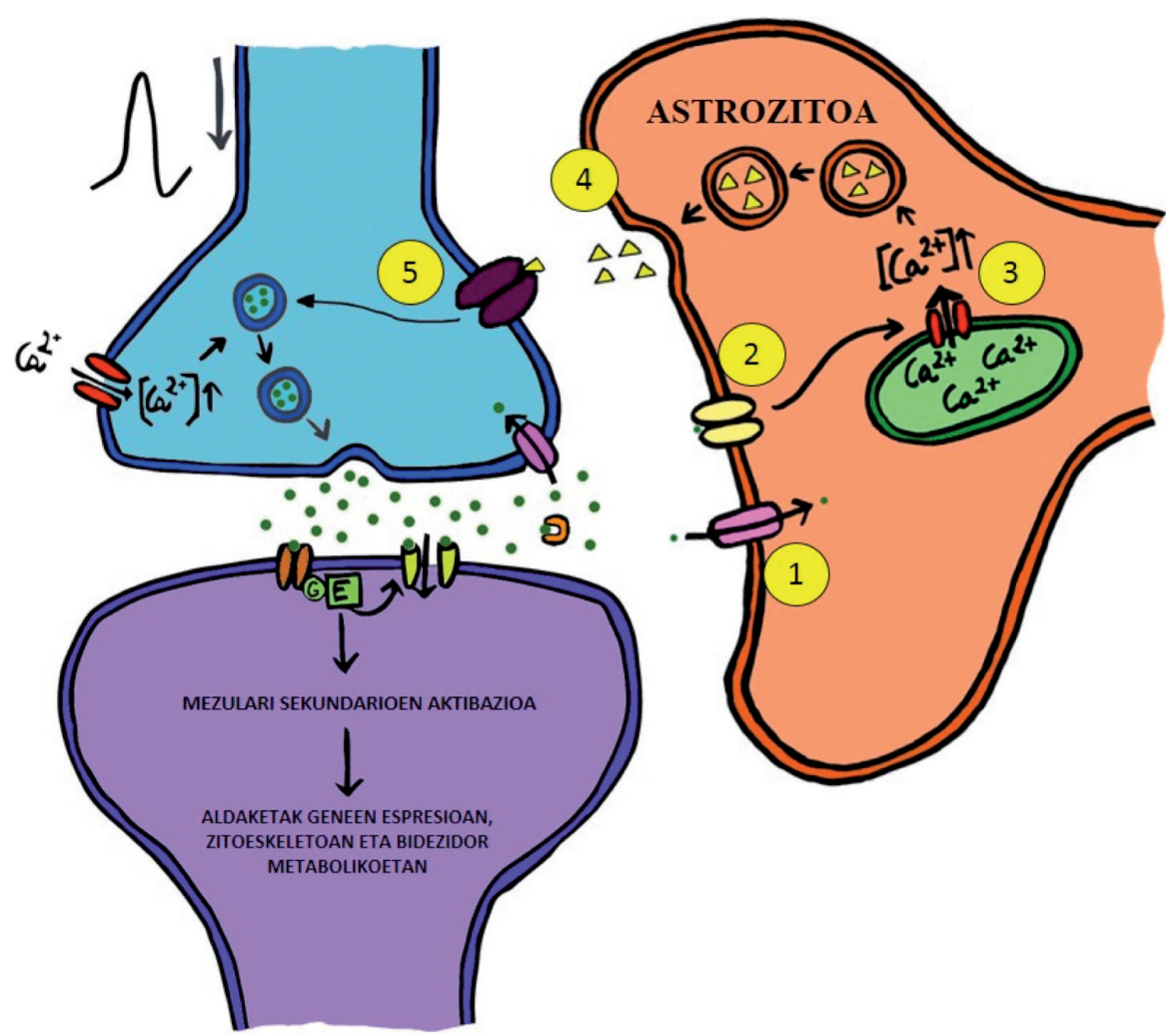

2. irudia. Sinapsi tripartitaren seinaleztapen-sistemaren eskema. 1) Neurotransmisorearen barneratzea astrozitoan proteina garraiatzaileen bidez. 2) Neurotransmisorearen lotura astrozitoan dagoen hartzailera eta horren ondorioz ematen den kaltzioaren askapena barne egituretatik. 3) Kaltzio kontzentrazio zitoplasmatikoaren igoerak eragindako besikulen fusioa mintz plasmatikoarekin. 4) Gliotransmisoreen askapena espazio sinaptikoan. 5) Gliotransmisorearen lotura neurona presinaptikoan dauden hartzaileetara eta ondorioz neurotransmisoreen askapenaren modulazioa. 


\section{SINAPSI TETRAPARTITA}

Sinapsiaren azken partaidea Alexander Dityatev eta Dmitri A. Rusakov ikertzaileek proposatu zuten 2011. urtean, eta nola ez, sinapsiaren kontzeptu berri honi sinapsi tetrapartita izena eman zioten. Haien teoriak, berezitasun bat du aurretik ikusitako teoriekin alderatuta: kasu honetan laugarren partaidea ez da zelula bat, molekula talde handi bat baizik, zelulaz kanpoko matrizea (ZKM)[16].

\subsection{Zelulaz kanpoko matrizea}

Zelulaz kanpoko matrizea ehun eta organo guztietan dagoen osagaia da, urez, polisakaridoz eta proteinez osatutakoa. Burmuinaren bolumenenaren \%20 hartzen duen eta garun zelulak inguratzen eta ainguratzen dituen sare molekularra osatzen du. Horretaz gain, ZKMko polisakarido eta proteinak seinaleztapen molekulak dira, zelulen morfologian, bereiztean eta homeostasian parte hartzen dutenak $[17,18]$. ZKMa neuronek eta zelula glialek sintetizatutako elementu ezberdin ugariz osatuta dagoenez, sare molekular sorta askotarikoak sortzen dira; horrela, garunean elementu bakoitzaren funtzioa eta eragina ezberdina da [19].

Garuneko ZKMa, bere osagaien arabera, 3 taldetan sailkatzen da. Talde bakoitzak nerbio-sistema zentralean (NSZ) kokapen zehatz bat du. Lehenik, mintz basaleko matrizea, muskulu leun baskularra eta parenkimako zelulak lotzen dituena. Bigarrenik, sare-perineuronala, neuronak, dendrita proximalak eta gliaren luzapenak inguratuz sinapsietan agertzen den dentsitate handiko eta sare-itxura hartzen duen geruza berezia. Azkenik, zelula parenkimatosoen artean kokapen zehaztugabearekin agertzen den matrize interstiziala [20, 21]. Haren kokapena eta egitura dela eta, haien artean sare perineuronala da sinapsian garrantzi handia duena; beraz, honetan sakonduko dugu.

Sare perineuronala osatzen duten molekulen artean proteoglikanoak (aggrecan, neurocan edota brevican proteinak, glikosaminoglikano kate bati lotuta), azido hialuronikoa, tensazina-R, reelin, lotura proteinak eta fibronektina daude, besteak beste. Molekula hauek plastikotasun sinaptikoan funtsezko papera betetzen dute, askotan beren arteko interakzioen ondorioz. Proteoglikanoak tenaszina-R bezalako molekulei lotzen zaizkie bere katearen mutur batetik, beste muturra lotura proteinen bidez azido hialuronikoari lotuta dagoen bitartean. Bere aldetik, azido hialuronikoa ez dago aske zelulaz kanpo, baizik eta mintz zelularrari ainguratuta. Gainera, tenaszina-R-ek proteoglikano kate askotarikoen lotura ahalbidetzen duen domeinu bat baino gehiago du eta horrela sare bat osatzen da, sare perineuronala [22-25]. (Ikus 3. irudia). 


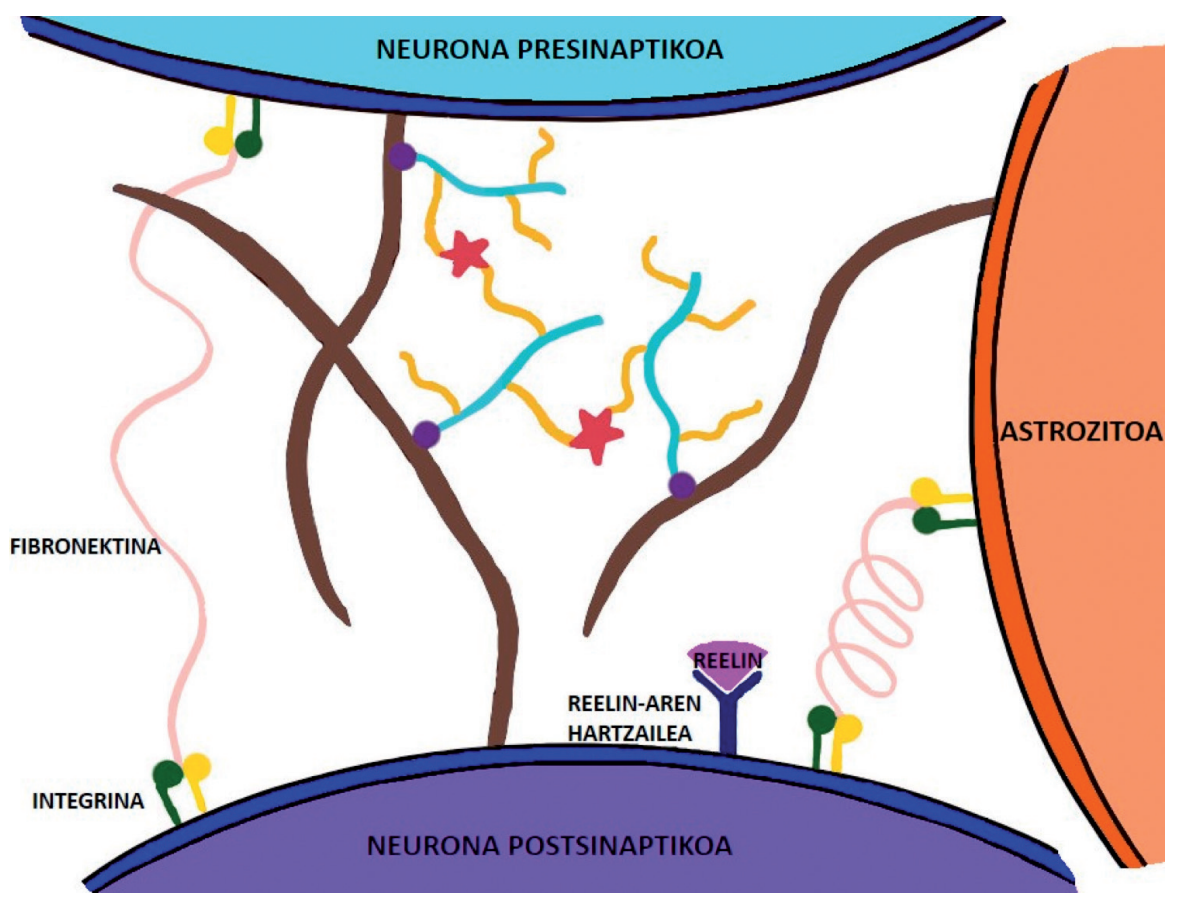

3. irudia. Sare perineuronalaren irudi eskematikoa: marroiz azido hialuronikoa; morez lotura proteinak, urdinez aggrecan, neurocan edota brevican proteinak; laranjaz glikosaminoglikano katea (kondroitin sulfatoa, adibidez) eta gorriz tenaszina-R.

\subsection{Zelulaz kanpoko matrizea nerbio sistemaren garapenean}

Enbrioien eta izaki gazteen ZKMak prozesu hauek ahalbidetzen ditu: neurogenesia eta gliogenesia (neuronen eta gliaren sorrera), migrazio zelularra, axoien hazkuntza, sinaptogenesia eta sinapsien berrantolaketa. Garuna garatzen ari den bitartean garun-azaleko zelulek geruza bakoitzean kokapen zehatz bat hartzen dute, migrazio zelularra deritzon prozesu baten bitartez. Ama zelula neuronalak (AZN) garun-azaleko geruza bentrikularrean kokatuta daude. AZN bakoitzak zelula erradial glialen (geruza bentrikularretik xafla basalera luzatzen diren bereiztu gabeko zelula glialak) luzapenak erabiliz xafla basalerako bidea egiten dute garun-azaleko geruzak zeharkatuz eta geruza egokian kokatuz [26]. ZKMko molekulak geruzetan banatuta daude migrazio zelularra eta AZNen bereiztea erregulatuz [27]. Hevin (edo SPARC-like 1) izeneko ZKMko proteina bat zelula erradial glialetan espresatzen da eta bere gaitasun itsasgaitzak neuronak zelula erradial glialetatik banatzen ditu eta ondorioz bere garun-azaleko hel- 
mugara zuzentzen ditu, migrazio zelularrari amaiera emanez [28]. Integrinak ZKMko molekula gehienen hartzaileak dira. Hauek zelulaz barruko seinaleztapenaren bidez migrazio zelularra eta axoien luzapena eta hazkuntza erregulatzen dituzte $[27,29]$.

Garun-azaleko migrazioaz gain, NSZren garapenean AZNak eta zelula erradial glialak neuronetan eta gliako zeluletan bereiziz doaz; prozesu honi neurogenesia eta gliogenesia deritzo, hurrenez hurren [30]. Bereiztearen prozesua oso konplexua da eta parte hartzen duten mekanismo asko argitzeko daude oraindik. Hala ere, egun badakigu ZKMko molekulek bereizte-prozesuan aktiboki parte hartzen dutela [31, 32]. Laminina eta fibronektina, ZKMko proteinak, integrina hartzaileetara lotuz zelulen hazkuntza eta bereiztea erregulatzen dute, integrinen bidezko loturak zelulaz barneko seinaleztatze-bidezidorrak aktibatzen dituelako eta ondorioz geneen espresioan eragiten duelako. Hartzaile-ZKM lotura hori zelularen arabera aldatzen da: izan ere, zelula bakoitzak ZKMko molekula eta hartzaile zehatzak izango ditu eta horrek zehaztuko du zelula bakoitzaren bereiztea zein izango den [32]. Bestalde, hazkunde-faktoreak ZKMko proteinetara lotu daitezke, zelulen migrazioa, hazkuntza eta bereiztea erregulatuz [33]. Gainera, hazkunde-faktoreak ZKMko proteina batzuen egituraren barne egon daitezke eta azken hauen entzimen bidezko mozketak neurogenesia erregula dezake hazkunde-faktoreak askatuz [34].

Sinaptogenesiari dagokionez, astrozito heldugabeek NSZa garatzen ari den bitartean tronpoespondina (TSP) izeneko ZKMko proteinak sintetizatzen dituzte. TSPak, oraindik ezezagunak diren beste ZKMko molekulen laguntzaz, sinapsi berriak sortzen dituzte sinapsietan molekula neuronalen muntaia ahalbidetuz [35]. Hevin eta SPARC proteinek (hevinen eta tronboespondinen familia bereko ZKMko proteina) sinaptogenesia erregulatzen dute. Hevin proteinak sinaptogenesia sustatzen du, SPARC efektu honen kontra egiten duen bitartean [36].

\subsection{Zelulaz kanpoko matrizea nerbio-sistema helduan}

Konexio neuronalak aldatuz doaz zahartzen garen heinean eta aldaketa horien arduradun garrantzitsu bat ZKMa da. Erdiostean ZKMa sare perineuronalak osatuz doa, garunaren zahartze prozesuan bere kopurua handitzen da, garunaren garapenean sortu diren konexio neuronalak egonkortzeko eta neurona helduetan sinapsi berrien formakuntza mugatzeko [37, 38].

Sare perineuronaleko ZKMak sinapsi kitzikatzaile eta inhibitzaileen formakuntza eta heltzea erregulatzeaz gain, helduetan plastikotasun sinaptikoa ZKMaren menpe dago [39]. Plastikotasun sinaptikoa esperientzia eta aktibitate aldaketek sinapsiaren indarrean, egituran eta funtzioan eragindako aldaketak dira. Honek nerbio-sistema ingurunera moldatzea 
errazten du, ikaste- eta memoria- prozesuak baimenduz [1, 40]. Helduen ZKMak plastikotasun sinaptikoa mugatzen du molekula inhibitzaileen bitartez [41]. Haien artean sare perineuronaleko kondroitin sulfato proteoglikanoak (KSPGak) eta azido hialuronikoa daude, zeinek, nahiz eta sinaptogenesia mugatu eta sinapsien berrantolakuntza blokeatu, mantentzen diren sinapsien egonkortasuna indartzen baitute $[42,43]$. Hala ere, plastikotasun sinaptikoa sustatzen duten ZKMko molekulak ere badaude. Esate baterako, sinapsi kitzikatzaileak inguratzen dituen sare perineuronalean dagoen brevican proteinak lanerako memoria eta epe laburreko memoria sustatzen ditu [44]. Esperientziak zirkuitu neuronalen egitura definitzen duen denbora tartea (aldi kritikoa) amaitzen denean ZKMak gaztea izatetik heldua izatera pasatzen da [41]. Sare perineuronalek batez ere sinapsi-inhibitzaileak inguratzen dituzte [45]. Sare perineuronal hauek aldi kritikoaren amaieran eragiten dutela iradoki da, beraren heltze prozesua aldi kritikoaren amaierarekin bat egiten duelako.

Sare perineuronalak sinapsi-inhibitzaileen heltzean parte hartzen dute eta haien aktibazio sinaptikoa modulatzen dute neurona inhibitzaileen potasio erretenen kokapena eta glutamatoarentzako hartzaileen kopurua kontrolatuz [37, 44, 45]. Adibidez, tenaszina-R proteinak hartzaile-inhibitzaileen aktibazio-gaitasuna handitzen duela ematen du [39]. Sinapsi-kitzikatzaileetan neurona postsinaptikoaren dendriten espezializazio sinaptikoa diren arantza dendritikoek parte hartzen dute. Sinapsiak duen indarra arantza dendritikoen epe luzeko aktibitate sinaptikoaren menpe dago, honek arantza dendritikoen tamaina eta ekintza potentzialaren transmisio gaitasuna alda ditzakeelako. Arantza dendritikoen zitoeskeletoaren parte den aktina proteinak haien tamaina eta forma kontrolatzen du eta hortaz, plastikotasun sinaptikoa [46, 47]. Baina zer-nolako eragina du ZKMak arantza dendritikoen hazkuntzan? Fibronektina bezalako ZKMko proteinak bere zelula gainazaleko hartzaile berezietara lotzen zaizkie, integrinei alegia. Lotura honek aktinaren formakuntza orekatzen du neurona postsinaptikoetan eta ondorioz, baita arantza dendritikoen egitura ere. Sinapsien testuinguruan, ZKM-integrina elkarrekintzak neurona postsinaptikoetan kokatzen diren neurotransmisore-hartzaile zehatz batzuen kopurua ere kontrolatzen du. Reelin izeneko zelulaz kanpoko matrize-proteinak, adibidez, integrinen bitarteko loturaren ondorioz glutamatoaren NMDA hartzaileen gainazaleko garraioa orekatzen du [47, 48].

Baina arantza dendritikoen plastikotasuna ez dago integrinen bidezko seinaleztapenaren menpe bakarrik. KSPGek, integrinen seinaleztapena inhibitzeaz gain, arantza dendritikoen mugimendua eta hazkuntza mugatzen dituzte, beren inguruan matrize zurruna eratuz eta honela, haien sinapsi kitzikatzaileen egonkortasuna bultzatuz. Hartzaileen bidezko seinaleztapenaren bidez ere arantza dendritikoen egitura kontrolatzen da. Adibidez, reelin bezalako ZKMko hainbat proteinak beraientzat espezifi- 
koak diren hartzaileetara lotuz zelulaz barneko seinaleztatze-bidezidorrak aktibatzen dituzte [47]. Hevin proteinak neurexina (proteina presinaptikoa) eta neuroligina (proteina postsinaptikoa) lotzen ditu [49]. Neurexinaren eta neuroliginaren arteko loturak neurona presinaptikoetan aktinaren polimerizazioa eragiten duen seinaleztatze-bidezidorra aktibatzen du. Aktinaren polimerizazioaren ondorioz, besikula sinaptikoen mugimendua eta neurotransmisoreen jariaketa gertatzen dela iradoki da [50]. Bi proteina horiek, berez, ezin dira lotu, baina hevinek zubi bat osatzen du haien artean, eta hortaz, sinapsi glutamatergikoen, formakuntza, egonkortasuna eta plastikotasuna sustatzen ditu $[49,51]$.

Zirkuito sinaptikoen birmoldaketa-prozesuak arantza dendritikoen kopuruan, morfologian eta sinapsien indarraren aldaketak barneratzen ditu [47]. Aldaketa horiek bizitzan zehar gertatzen dira ikaste- eta memoria-prozesuetan, esate baterako. Garunean plastikotasun sinaptikoa errazteko ZKMa birmoldatzen duten entzimak daude [52]. Haien artean, matrizeko metaloproteinasak (MMP) izeneko zelulaz kanpoko entzima proteolitikoak daude. MMPak ZKMko proteinak eta zelula gainazaleko molekulak moztu ditzakete. Mozketaren ondorioz sortzen diren hainbat molekularen zatiak plastikotasun sinaptikoa gertatzeko ezinbestekoak diren zelulaz kanpoko mezulariak dira [53]. Integrinari lotzen zaizkion ZKMko proteinen mozketak neurona-ZKM lotura aldatzen dute, eta, beraz egitura sinaptikoan eragiten dute $[54,55]$. Bestalde, MMPak plastikotasun sinaptikoa sustatzen dute, eta ondorioz, beharrezkoak dira memoria eta ikaste-gaitasun egokiak izateko [56]. Kondroitinasa ABC entzimak KSPGen deuseztatzea eragiten du, hortaz, sinapsi kitzikatzaileen arantza dendritikoen mugikortasuna eta hazkuntza bultzatzen ditu eta neurona inhibitzaileen kopurua handitzen du memoria prozesua hobetuz $[57,58]$. Arantza dendritikoen formazioa eragiten duen beste entzima bat neurotripsina da. Neurotripsina neurona presinaptikoek askatutako entzima bat da eta ZKMko agrin proteina bi zatitan mozten du sinapsietan. Bi zati horietatik bat neurona postsinaptikoaren arantza dendritikoen formazioaren arduraduna da [59].

Plastikotasun sinpatikoan parte hartzeaz gain, ZKMko molekulek neuronen mielinizazioa sustatzen dute eta ZKMak espazio sinaptikoan osatzen duen sare molekularrak neurona presinaptikoaren eta postsinaptikoaren arteko loturak mugatzen edo sustatzen ditu. Horretaz gain, molekulen, ioien eta mintzean zeharreko hartzaileen difusioa eragozten du; alde batetik, neurotransmisoreen eta hartzaile postsinaptikoen arteko loturari trabak jarriz; eta bestetik, ZKMak neurotransmisoreen birzurgapena oztopatuz eta haiek espazio sinaptikoan geratzen diren denbora luzatuz [60-64]. 


\subsection{Zelulaz kanpoko matrizearen garrantzia gaixotasun neurologikoetan}

Ikerkuntza asko ZKMko alterazioak neurogarapeneko zenbait gaixotasunekin eta gaitz neuropsikiatrikoekin erlazionatzen ari dira. Eta beraz, aurkikuntza hauek garun-patologiak ulertzeko aurrepauso handia ekar dezakete. Are gehiago, ZKMak sinapsietan dituen funtzio asko gaitz neuronaletan ikusitako alterazioetan oinarrituta daude, ZKMaren aldaketak hainbat alterazio neuronal eragiten baitituzte.

Eskizofrenian dagoen patologia sinaptikoa, adibidez, KSPGen eta reelin proteinaren espresioaren anormaltasunekin lotuta dago $[65,66]$. Era berean, autismoan hevin espresatzen duten geneen mutazioak ikusi dira eta, ondorioz, zirkuito neuronalen alterazioak [49]. Bestalde, memoriaren eta ikasteko gaitasunaren arloetan, azido hialuronikoaren entzimaren bidezko degradazioak ikasteko gaitasuna murrizten du; eta tensazina-R proteinaren gabeziak, aldiz, ikasteko gaitasuna, lanerako memoria eta objektuen antzematea hobetzen ditu [63, 67]. Alzheimer gaixotasunean proteina batzuen agregatuak sortu eta pilatzen dira neuronen kanpoaldean eta barnealdean. Agregatu horiek ZKMak eratutako aldamioa kaltetu dezakete, brevican proteinan eraginez, adibidez. Alzheimerrean dagoen brevican proteinaren murrizpena heriotza neuronalarekin lotzen da, baina kalte hauei aurre egiten dioten ZKMko beste proteina batzuk, aldiz, nolabaiteko endekapen neuronalaren aurkako babesa ematen dute. Aggrecan-ek eta tenaszina-R-ek babes ezaugarri horiek erakutsi dituzte [68, 69]. Hala ere, kondroitinasa ABC entzimak eragindako ZKMaren eliminazioa Alzheimerrean plastikotasun sinaptikoa eta memoria hobetzen ditu [70].

Bestalde, zelula glial jakin batzuek, oligodendrozitoek, axoiak inguratzen dituen eta ekintza potentzialaren garraioa azkartzen eta babesten duen mielina-zorroa eratzen dute. Esklerosi anizkoitzean eta Alzehimer gaixotasunean kalte neuronalek KSPGetan eragiten dituzten alterazioen ondorioz mielinaren birsorkuntza inhibituta dago [23]. Metaloproteinasen alterazioak ere hainbat gaitzekin lotu dira, besteak beste hauekin: X hauskorraren sindromearekin (heredatutako autismoaren eta adimen-urritasunaren formarik ohikoena), drogekiko menpekotasunarekin eta Alzheimer gaixotasunarekin $[53,71,72]$.

\section{ONDORIOAK}

ZKMa sinapsi tetrapartitaren laugarren partaidea da, honek osatzen dituen sare perineuronalek gorputz neuronalak, dendritak eta zelula glialen luzapenak inguratzeaz gain, aktibitate eta plastikotasun sinaptikoan eragiten dutelako. ZKMa unitate sinaptikoaren partaide izateak sinapsiak osatzen dituzten lau egituren arteko seinaleztapen bideak bikoizten ditu [16]. Horretaz 
gain, ZKMko molekulen aniztasunak konexio neuronalen funtzionamendua konplexuagoa egiten du. ZKMko molekulen eta hauek degradatzen dituzten entzimen alterazioak disfuntzio neuronalekin eta gaixotasun eta gaitz neuropsikiatrikoekin erlazionatu dira. Baina oraindik egitura honi buruz daukagun ezagutza eskasa da. Beraz, konexio neuronalen eta garunaren funtzionamendua deszifratzeko, funtsezkoa da ZKMaren inguruan ikertzen jarraitzea.

\section{BIBLIOGRAFIA}

[1] KATZ LC, SHATZ CJ. 1996. «Synaptic Activity and the Construction of Cortical Circuits». Science, 274, 1133-8.

[2] PRESUMEY J, BIALAS AR, CARROLL MC. 2017. «Chapter Two - Complement System in Neural Synapse Elimination in Development and Disease». Advances in Immunology, 135, 53-79.

[3] GOLAN DE, TASHJIAN AH, ARMSTRONG EJ. 2011. Principles of pharmacology: the pathophysiologic basis of drug therapy. Lippincott Williams \& Wilkins. Philadelphia.

[4] KEW JNC, KEMP JA. 2005. «Ionotropic and metabotropic glutamate receptor structure and pharmacology». Psychopharmacology, 179, 4-29.

[5] PURVES D, AUGUSTINE GJ, FITZPATRICK D, KATZ LC, LAMANTIA A-S, MCNAMARA JO, ET AL. 2001. Neuroscience. 2nd edition. Neurotransmitter Release and Removal. Sinauer Associates, Sunderland (MA).

[6] ALLEN NJ, BARRES BA. 2009. «Neuroscience: Glia - more than just brain glue». Nature, 457, 675-7.

[7] NEDERGAARD M, RANSOM B, GOLDMAN SA. 2003. «New roles for astrocytes: Redefining the functional architecture of the brain». Trends Neurosci., 26, 523-30.

[8] BLACKBURN D, SARGSYAN S, MONK PN, SHAW PJ. 2009. «Astrocyte function and role in motor neuron disease: A future therapeutic target?». Glia, 57, 1251-64.

[9] MENNERICK S, ZORUMSKI CF. 1994. «Glial contributions to excitatory neurotransmission in cultured hippocampal cells». Nature, 368, 59-62.

[10] STOBART JL, ANDERSON CM. 2013. «Multifunctional role of astrocytes as gatekeepers of neuronal energy supply». Front Cell Neurosci., 7, 1-21.

[11] ARAQUE A, PARPURA V, SANZGIRI RP, HAYDON PG. 1999. «Tripartite synapses: glia, the unacknowledged partner». Trends Neurosci., 22, $208-15$.

[12] ZHOU Y, DANBOLT NC. 2014. "Glutamate as a neurotransmitter in the healthy brain». J Neural Transm., 121, 799-817.

[13] DE PITTÀ M, VOLMAN V, BERRY H, PARPURA V, VOLTERRA A, BEN-JACOB E. 2012. «Computational quest for understanding the role of astrocyte signaling in synaptic transmission and plasticity». Front Comput Neurosci., 6, 1-25. 
[14] DALLÉRAC G, CHEVER O, ROUACH N. 2013. «How do astrocytes shape synaptic transmission? Insights from electrophysiology». Front Cell Neurosci., 7, 1-19.

[15] GENOUD C, QUAIRIAUX C, STEINER P, HIRLING H, WELKER E, KNOTT GW. 2006. «Plasticity of Astrocytic Coverage and Glutamate Transporter Expression in Adult Mouse Cortex». PLoS Biol., 4, 2057-64.

[16] DITYATEV A, RUSAKOV DA. 2011. «Molecular signals of plasticity at the tetrapartite synapse». Curr Opin Neurobiol., 21, 353-9.

[17] FRANTZ C, STEWART KM, WEAVER VM. 2010. «The extracellular matrix at a glance». J Cell Sci., 123, 4195-200.

[18] NICHOLSON C, KAMALI-ZARE P, TAO L. 2011. «Brain Extracellular Space as a Diffusion Barrier». Comput Vis Sci., 14, 309-25.

[19] Kwok Jcf, Dick G, Wang D, Fawcett Jw. 2011. «Extracellular matrix and perineuronal nets in CNS repair». Dev Neurobiol., 71, 1073-89.

[20] LAU LW, CUA R, KEOUGH MB, HAYLOCK-JACOBS S, YONG VW. 2013. «Pathophysiology of the brain extracellular matrix: a new target for remyelination». Nat Rev Neurosci., 14, 722-9.

[21] CELIO MR, BLUMCKE I. 1994. «Perineuronal nets - a specialized form of extracellular matrix in the adult nervous system». Brain Res Rev., 19, 128-45.

[22] KARETKO M, SKANGIEL-KRAMSKA J. 2009. «Diverse functions of perineuronal nets». Acta Neurobiol Exp (Warsz), 69, 564-77.

[23] KOROTCHENKO S, CELLA ZANACCHI F, DIASPRO A, DITYATEV A. 2014. «Zooming in on the (Peri)synaptic Extracellular Matrix».Nanoscale Imaging of Synapses, Neuromethods, 84, 187-203.

[24] ANLAR B, GUNEL-OZCAN A. 2012. «Tenascin-R: Role in the central nervous system». Int J Biochem Cell Biol., 44, 1385-9.

[25] BIGNAMI A, HOSLEY M, DAHL D. 1993. «Hyaluronic acid and hyaluronic acid-binding proteins in brain extracellular matrix». Anat Embryol (Berl)., 188, 419-33.

[26] NADARAJAH B. 2003. «Neuronal Migration in the Developing Cerebral Cortex: Observations Based on Real-time Imaging». Cereb Cortex., 13, 607-11.

[27] BARROS CS, FRANCO SJ, MULLER U. 2011. «Extracellular Matrix: Functions in the Nervous System». Cold Spring Harb Perspect Biol., 3, 1-24.

[28] GONGIDI V, RING C, MOODY M, BREKKEN R, SAGE EH, RAKIC $\mathrm{P}$, et al., 2004. «SPARC-like 1 regulates the terminal phase of radial gliaguided migration in the cerebral cortex». Neuron., 41, 57-69.

[29] DEFREITAS MF, YOSHIDA CK, FRAZIER WA, MENDRICK DL, KYPTA RM, REICHARD LF. 1995. «Identification of integrin $\alpha 3 \beta 1$ as a neuronal thrombospondin receptor mediating neurite outgrowth». Neuron., 15, 333-43.

[30] MALATESTA P, APPOLLONI I, CALZOLARI F. 2008. «Radial glia and neural stem cells». Cell Tissue Res., 331, 165-78. 
[31] ARULMOLI J, PATHAK MM, MCDONNELL LP, NOURSE JL, TOMBOLA F, EARTHMAN JC, ET AL. 2015. «Static stretch affects neural stem cell differentiation in an extracellular matrix-dependent manner». Sci Rep., $\mathbf{5}, 1-8$.

[32] WOJCIK-STANASZEK L, GREGOR A, ZALEWSKA T. 2011. «Regulation of neurogenesis by extracellular matrix and integrins». Acta Neurobiol Exp (Warsz), 71, 103-12.

[33] IYER AKV, TRAN KT, GRIFFITH L, WELLS A. 2008. «Cell surface restriction of EGFR by a tenascin cytotactin-encoded EGF-like repeat is preferential for motility-related signaling». J Cell Physiol., 214, 504-12.

[34] SCHENK S, QUARANTA V. 2003. «Tales from the crypt[ic] sites of the extracellular matrix». Trends Cell Biol., 13, 366-75.

[35] CHRISTOPHERSON KS, ULLIAN EM, STOKES CCA, MULLOWNEY CE, HELL JW, AGAH A, ET AL. 2005. «Thrombospondins Are AstrocyteSecreted Proteins that Promote CNS Synaptogenesis». Cell, 120, 421-33.

[36] CHUNG W-S, ALLEN NJ, EROGLU C. 2015. «Astrocytes Control Synapse Formation, Function, and Elimination». Cold Spring Harb Perspect Biol., 7, 1-18.

[37] BAKER KD, GRAY AR, RICHARDSON R. 2017. «The development of perineuronal nets around parvalbumin gabaergic neurons in the medial prefrontal cortex and basolateral amygdala of rats». Behav Neurosci., 131, 289303.

[38] MCRAE PA, PORTER BE. 2012. «The perineuronal net component of the extracellular matrix in plasticity and epilepsy». Neurochem Int., 61, 963-72.

[39] DITYATEV A, IRINTCHEV A, MORELLINI F, SCHACHNER M. 2009. Extracellular Matrix Molecules: Synaptic Plasticity and Learning. Encyclopedia of Neuroscience. Academic Press, Oxford.

[40] BUONOMANO DV, MERZENICH MM. 1998. «CORTICAL PLASTICITY: From Synapses to Maps». Annu Rev Neurosci., 21, 149-86.

[41] FAWCETT J. 2009. «Molecular control of brain plasticity and repair». Progress in Brain Research, 175, 501-9.

[42] DE VIVO L, LANDI S, PANNIELLO M, BARONCELLI L, CHIERZI S, MARIOTTI L, ET AL. 2013. «Extracellular matrix inhibits structural and functional plasticity of dendritic spines in the adult visual cortex». Nat Commun., 4, 1484-94.

[43] BIKBAEV A, FRISCHKNECHT R, HEINE M. 2015. «Brain extracellular matrix retains connectivity in neuronal networks». Sci Rep., 5, 1-12.

[44] FAVUZZI E, MARQUES-SMITH A, DEOGRACIAS R, WINTERFLOOD CM, SÁNCHEZ-AGUILERA A, MANTOAN L, ET AL. 2017. «ActivityDependent Gating of Parvalbumin Interneuron Function by the Perineuronal Net Protein Brevican». Neuron., 95, 639-655.

[45] MCRAE PA, ROCCO MM, KELLY G, BRUMBERG JC, MATTHEWS RT. 2007. «Sensory Deprivation Alters Aggrecan and Perineuronal Net Expression in the Mouse Barrel Cortex». J Neurosci., 27, 5405-13. 
[46] PENZES P, RAFALOVICH I. 2012. «Regulation of the actin cytoskeleton in dendritic spines». Adv Exp Med Biol., 970, 81-95.

[47] LEVY AD, OMAR MH, KOLESKE AJ. 2014. «Extracellular matrix control of dendritic spine and synapse structure and plasticity in adulthood». Front Neuroanat., 8, 1-18.

[48] GROC L, CHOQUET D, STEPHENSON FA, VERRIER D, MANZONI OJ, CHAVIS P. 2007. «NMDA Receptor Surface Trafficking and Synaptic Subunit Composition Are Developmentally Regulated by the Extracellular Matrix Protein Reelin». J Neurosci., 27, 10165-75.

[49] SINGH SK, STOGSDILL JA, PULIMOOD NS, DINGSDALE H, KIM YH, PILAZ L-J, ET AL. 2016. «Astrocytes Assemble Thalamocortical Synapses by Bridging Nrx1 $\alpha$ and NL1 via Hevin». Cell., 164, 183-96.

[50] RUI M, QIAN J, LIU L, CAI Y, LV H, HAN J, et al. 2017. «The neuronal protein Neurexin directly interacts with the Scribble - Pix complex to stimulate Factin assembly for synaptic vesicle clustering». J Biol Chem., 292, 14334-48.

[51] KUCUKDERELI H, ALLEN NJ, LEE AT, FENG A, OZLU MI, CONATSER LM, et al. 2011. "Control of excitatory CNS synaptogenesis by astrocyte-secreted proteins Hevin and SPARC». Proc Natl Acad Sci U S A., 108, 440-449.

[52] KURSHAN PT, PHAN AQ, WANG GJ, CRANE MM, LU H, SHEN K. 2014. «Regulation of Synaptic Extracellular Matrix Composition Is Critical for Proper Synapse Morphology». J Neurosci., 34, 12678-89.

[53] SMITH ACW, SCOFIELD MD, KALIVAS PW. 2015. «The tetrapartite synapse: extracellular matrix remodeling contributes to corticoaccumbens plasticity underlying drug addiction». Brain Res., 1628, 29-39.

[54] MICHALUK P, MIKASOVA L, GROC L, FRISCHKNECHT R, CHOQUET D, KACZMAREK L. 2009. «Matrix Metalloproteinase-9 Controls NMDA Receptor Surface Diffusion through Integrin 1 Signaling». J Neurosci., 29, 6007-12.

[55] ETHELL IM, ETHELL DW. 2007. «Matrix metalloproteinases in brain development and remodeling: Synaptic functions and targets». J Neurosci Res., 85, 2813-23.

[56] FUJIOKA H, DAIRYO Y, YASUNAGA K, EMOTO K. 2012. «Neural Functions of Matrix Metalloproteinases: Plasticity, Neurogenesis, and Disease [Internet]. Biochemistry Research International. 2012, 1-8.

[57] ORLANDO C, STER J, GERBER U, FAWCETT JW, RAINETEAU O. 2012. «Perisynaptic Chondroitin Sulfate Proteoglycans Restrict Structural Plasticity in an Integrin-Dependent Manner». J Neurosci Off J Soc Neurosci., 32, 18009-17.

[58] DONATO F, ROMPANI SB, CARONI P. 2013. «Parvalbumin-expressing basket-cell network plasticity induced by experience regulates adult learning». Nature, 504, 272-6.

[59] MATSUMOTO-MIYAI K, SOKOLOWSKA E, ZURLINDEN A, GEE CE, LÜSCHER D, HETTWER S, ET AL. 2009. «Coincident Pre- and Postsy- 
naptic Activation Induces Dendritic Filopodia via Neurotrypsin-Dependent Agrin Cleavage». Cell, 136, 1161-71.

[60] KOLESKE AJ. 2013. «Molecular mechanisms of dendrite stability». Nat Rev Neurosci., 14, 536-50.

[61] FRISCHKNECHT R, HEINE M, PERRAIS D, SEIDENBECHER CI, CHOQUET D, GUNDELFINGER ED. 2009. «Brain extracellular matrix affects AMPA receptor lateral mobility and short-term synaptic plasticity». Nat Neurosci., 12, 897-904.

[62] STYLIANOPOULOS T, POH M-Z, INSIN N, BAWENDI MG, FUKUMURA D, MUNN LL et al. 2010. «Diffusion of Particles in the Extracellular Matrix: The Effect of Repulsive Electrostatic Interactions». Biophys J., 99, 1342-9.

[63] WLODARCZYK J, MUKHINA I, KACZMAREK L, DITYATEV A. 2011. «Extracellular matrix molecules, their receptors, and secreted proteases in synaptic plasticity». Dev Neurobiol., 71, 1040-53.

[64] HERMAN MA, JAHR CE. 2007. «Extracellular Glutamate Concentration in Hippocampal Slice». J Neurosci., 27, 9736-41.

[65] CHELINI G, PANTAZOPOULOS H, DURNING P, BERRETTA S. 2018. «The tetrapartite synapse: a key concept in the pathophysiology of schizophrenia». Eur Psychiatry, 50, 60-9.

[66] BERRETTA S. 2012. «Extracellular Matrix Abnormalities in Schizophrenia». Neuropharmacology, 62, 1584-97.

[67] MORELLINI F, SIVUKHINA E, STOENICA L, OULIANOVA E, BUKALO O, JAKOVCEVSKI I, ET AL. 2010. «Improved Reversal Learning and Working Memory and Enhanced Reactivity to Novelty in Mice with Enhanced GABAergic Innervation in the Dentate Gyrus». Cereb Cortex, 20, 2712-27.

[68] MORAWSKI M, BRÜCKNER G, JÄGER C, SEEGER G, MATTHEWS RT, ARENDT T. 2012. «Involvement of Perineuronal and Perisynaptic Extracellular Matrix in Alzheimer's Disease Neuropathology». Brain Pathol Zurich Switz, 22, 547-61.

[69] SUTTKUS A, ROHN S, WEIGEL S, GLÖCKNER P, ARENDT T, MORAWSKI M. 2014. «Aggrecan, link protein and tenascin-R are essential components of the perineuronal net to protect neurons against iron-induced oxidative stress». Cell Death Dis., 5, e1119.

[70] VÉGH MJ, HELDRING CM, KAMPHUIS W, HIJAZI S, TIMMERMAN AJ, LI KW, ET AL. 2014. «Reducing hippocampal extracellular matrix reverses early memory deficits in a mouse model of Alzheimer's disease». Acta Neuropathol Commun, 2, 76.

[71] HUNTLEY GW. 2012. «Synaptic circuit remodelling by matrix metalloproteinases in health and disease». Nat Rev Neurosci, 13, 743.

[72] STOMRUD E, BJÖRKQVIST M, JANCIAUSKIENE S, MINTHON L, HANSSON O. 2010. "Alterations of matrix metalloproteinases in the healthy elderly with increased risk of prodromal Alzheimer's disease». Alzheimers Res Ther, 2, 20-28. 
